Geller, E.S., Berry, T.D., Ludwig, T.D, Evans, R.E., Gilmore, M.R., \& Clarke, S.W. (1990). A Conceptual Framework for Developing and Evaluating Behavior Change Interventions for Injury Control. Health Education Research: Theory and Practice, 5 (2), 125-137. (ISSN: 02681153) Published by Oxford University Press doi:10.1093/her/5.2.125

\title{
A Conceptual Framework for Developing And Evaluating Behavior Change Interventions For Injury Control
}

\author{
E. Scott Geller, Thomas D.Berry, Timothy D. Ludwig, Robert E. Evans, \\ Michael R. Gilmore and Steven W. Clarke
}

\begin{abstract}
This paper addresses issues and research needs in the domain of behavior modification for injury control. Although much of the discussion focuses on traffic safety, the concepts and principles are applicable to all areas of injury control (e.g. on the job and in the home). Field research that has increased safety belt use is reviewed briefly to illustrate a tripartite classification of injury control factors (i.e. environmental, individual, or behavioral variables), and to introduce a heuristic framework for categorizing and evaluating behavior change strategies. $A$ multiple intervention level hierarchy depicts a progressive segmentation of the target population as more effective (and costly) interventions are implemented; and a taxonomy of 24 behavior change techniques includes a scoring system for predicting short and long term effects of intervention programs. It is presumed that more risk-prone individuals require higher-level interventions, which are those that provide specific response information and extrinsic controls, while also eliciting active participant involvement, social support, and perceptions of autonomy. Although extrinsic controls increase the immediate impact of an intervention program, these techniques may jeopardize response maintenance when the program is withdrawn.
\end{abstract}




\section{ARTICLE}

Injury is physical harm to a person caused by exchanges with environmental energy; the mechanicalenergy exchanges in falls, shootings and motor vehicle crashes are the most common causes of severe and fatal injuries (Robertson, 1983). In the United States, injury is the prime cause of lost years of productive life (Waller, 1987). In fact, the number of years lost annually to injuries of Americans exceed those lost from cancer by 2.4 million years and from heart disease by 2.0 million years of life (Injury in America, 1985). The factors contributing to an injury can be categorized as person, behavior and environment variables. Figure 1 illustrates these three factors wiui examples from the domains of occupational and vehicle safety. Geller et al. (1989) termed this figure "The Safety Triad', and developed this model as a foundation for a training program to prevent occupational injuries.

The person factors are the most difficult to identify as causes of injury, since these factors are numerous and most are not directly observable. For example, an individual's prior training or experience, or his/her attitude may have influenced the injury producing incident. Alternatively, a person's particular skills, abilities, intelligence or physical condition (e.g. as affected by lack of sleep or substance abuse) could have an impact. Furthermore, a risky lifestyle or personality (e.g. Donovan et al., 1983; Wilson and Jonah, 1988) increases one's propensity to emit injury-prone behaviors.

The environmental conditions that are potential contributors to injury are relatively easy to identify and modify because they are observable and finite. The presence of equipment hazards fall under this category, as well as the availability or absence of various safeguards (e.g. power lockout devices on equipment or safety glasses worn by an individual). Adding safety devices to the environment (e.g. automatic safety belts and air bags in automobiles) 


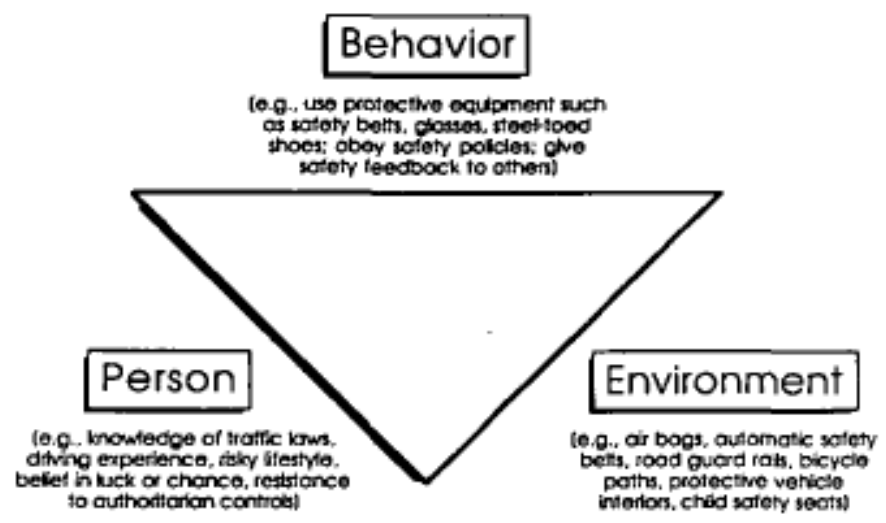

Fig. 1. A tripartite classification of factors contributing to personal injury. While the examples are specific to traffic safety, the concepts are relevant to all problem domains that can benefit from behavior change.

is considered an optional approach to injury control (cf. Robertson, 1983), because such modifications require no additional behaviors or inconvenience by those protected.

The responses people emit or fail to emit in order to prevent potential injuries are represented by the behavior side of the triangle depicted in Figure 1. Whereas a one-time change in the environment (e.g. installing a guard rail or an automobile air bag) can result in long-term protection, safety behaviors (e.g. using vehicle safety belts and travelling in the appropriate highway lane) usually need to be repeated many times for effective injury control. Like environmental factors, behaviors can be observed, recorded objectively and subsequently modified to reduce injury potential. Changes in the environment (e.g. lane markers, safety reminder signs, traffic lights) or the person (e.g. through training or experience) influence behavior change with varying degrees of probability or certainty. Purposive changes in environmental settings or stimulus-response consequence contingencies to influence behaviors are termed behavior change interventions.

The present paper focuses on behavior change to prevent injuries, with a prime goal to present a framework for designing large-scale injury control programs and for evaluating the impact of such programs. Although most of the examples cited here are 
within the domain of traffic safety (especially safety belt promotion), the concepts and principles are relevant for all areas of injury control (from the home to the workplace, as well as on-the-road). The behavior change research in the domain of safety belt promotion is substantial, because safety belt use is readily observable in the field and is probably the most convenient and protective health behavior to emit (e.g. Geller, 1990; Sleet, 1987).

\section{Interventions for increasing safety belt use}

Policies and mandates

Policies and mandates are usually written statements that define the standards, norms or rules for appropriate performance or behavior within a given context. Many factors influence the behavioral impact of a policy, including promotional campaigns, the type and extent of enforcement procedures, the environmental context, and various characteristics of those individuals required to comply with the policy. In other words, the degree of compliance with a policy (i.e. the behavior side of Figure 1) is determined by relevant environmental factors, person factors and their interaction.

Legislative attempts to increase safety belt use have decreased injuries and fatalities from vehicle crashes, but much more behavior change is necessary. Safety belt use has increased dramatically in virtually every state of the United States that has passed a belt use law (BUL). During the last 6 months of 1985, for example, observations of front-seat occupants in 17 states without a BUL revealed $21.6 \%$ using safety belts (Zeigler, 1986); whereas, mean post-BUL belt use across states with BULs was $48 \%$ in 1986 (Campbell et al., 1987) and 47\% in 1987 (Campbell etai, 1988). In 1989, the 19-city study conducted annually by the National Highway Traffic Safety Administration found an average of $50.4 \%$ safety belt use across the 13 cities in states with a BUL and $33.4 \%$ belt use in the six cities located in states without BULs (Schweitz, personal communication January 17, 1990). Interventions are obviously needed to make environments more supportive and people more receptive of BULs. For example, the low use of safety belts on US television (e.g. < 25\% throughout the 1984-1988 seasons: Geller, 1988, 1989a) sets inappropriate examples for viewers and 
reflects a non-supportive milieu for a BUL.

It is generally believed that the drivers most apt to comply with speed limits and traffic laws are the first to comply with a BUL. Therefore, me most prominent decreases in injuries from vehicle crashes won't occur until those currently resisting the beltuse mandates buckle up (Campbell et al., 1987). In other words, 'those segments of the driving population who are least likely to comply with safe driving laws are precisely those groups that are at highest risk of serious injury' (Waller, 1987, p. 43). This presumed direct relationship between risky behavior and noncompliance with behavior change policy has empirical support in that young males (Preusser et al., 1985), persons with elevated blood alcohol consumption (Wagenaar, 1984), and drivers with unsafe headway distances between their vehicles and the vehicles they are following (Evans et al., 1982) are least likely to comply with a BUL.

\section{Applied behavior analysis}

The antecedent-behavior-consequence model of applied behavior analysis has been applied rather frequently and successfully over recent years to increase safety belt use (e.g. see reviews by Geller, 1988, 1989b, 1990). Indeed, behavior analysts have designed successful education, feedback, reminder, commitment, incentive and reward strategies for increasing safety belt use that have been used nationwide by numerous traffic safety professionals and grass roots organizations. As with BULs, the impact of these behavior change interactions is influenced by complex interactions between environmental and person factors.

\section{Incentives/rewards}

Most of the incentive-based programs for safety belt promotion have involved the direct and immediate delivery of small prizes to vehicle occupants observed using their safety belts (e.g. see review by Geller, 1984). These programs have targeted adults in vehicles at entrances/exits to industrial complexes (e.g. Campbell et al., 1982; Geller, 1983), at the exchange windows of banks (Geller, Johnson and Pelton, 1982) and at the entrances to the parking lots of high schools (Campbell et al., 1984), a university 
(Geller, Paterson and Talbot, 1982) and a shopping mall (Elman and Killebrew, 1978). Also, Roberts and his colleagues have successfully applied immediate reward strategies to increase children's use of child safety seats and safety belts (e.g. Roberts and Fanurik, 1986; Roberts and Turner, 1986; Roberts and Layfield, 1987). Whether targeting adults or children, when reward programs were withdrawn, safety belt use declined prominently, but usually remained significantly higher than preintervention baseline levels.

\section{Awareness sessions and pledge cards}

Geller et al. (1987) reviewed five corporate safety belt programs that did not use rewards, but applied an interactive small-group discussion format. After a 20-25 min group discussion, buckle up pledge cards were distributed and participants were urged by the group facilitator and by other participants to make a buckle up commitment. When the participants left the room they deposited a portion of each signed pledge card into a 'pledge box'. After comparing these programs with 13 reward programs, Geller et al. (1987) concluded that the immediate behavorial effects of the reward versus no-reward programs were equivalent. After these programs terminated, however, there was consistently greater maintenance of safety belt use for the no-reward programs. Similarly, Lehman and Geller (1990) recently found substantial long term increases in the safety belt use of children and their parents following special participative educational sessions.

Several theoretical formulations and laboratory investigations suggest that extrinsic rewards may not be an optimal approach for motivating lasting behavior change. Indeed, the conceptualization and investigation of the 'minimal justification principle' (Lepper, 1981), 'overjustification' (e.g. Lepper et al., 1973), 'intrinsic motivation' (Deci, 1975), 'autonomy support' (Deci and Ryan, 1987) and 'self efficacy' (Bandura, 1989) predict greater long term behavior change with interventions that minimize extrinsic controls. Powerful extrinsic motivators are assumed to inhibit individuals from gaining an internal justification for performing the target behavior after the external controls are withdrawn. Clearly, more research is needed to define the parameters for obtaining enough extrinsic control to 
initiate the buckle-up response, but not too much so as to diminish perceived internal control and intrinsic justification.

\section{Signs}

Written messages have been found to increase the occurrence of desirable behaviors when the message politely requests the occurrence of a specific response that is relatively convenient to emit (e.g. see review by Geller, Winett and Everett, 1982). For example, the display of a sign with the bold message,

'PLEASE BUCKLE UP-I CARE', significantly increased safety belt use when displayed in close proximity to an opportunity to comply with the polite request (Geller et al, 1985; Thyer et al, 1987).

\section{Feedback}

The behavior change literature has shown beneficial effects of posting information that displays the performance levels of a community. For example van Houten and his colleagues (e.g. van Houten et al., 1980; van Houten and Nau, 1983) found that community signs posting the daily percentages of drivers exceeding the speed limit increased the percentage of drivers who subsequently complied with the speed limit. Likewise, Jonah (1989) reported a study that showed significant increases in safety belt use following the posting of roadway signs that displayed 'percentage of drivers wearing seat belts yesterday'.

\section{A multiple intervention level hierarchy}

Although an arsenal of behavior change strategies is available for preventing injuries [as reviewed briefly above for safety belt promotion, and reviewed more extensively elsewhere, e.g. Streff and Geller (1986); Geller (1988, 1990); Thyer and Geller (in press)], there has been little attempt to categorize these procedures in terms of relative effectiveness, particularly with regard to resistant subgroups or individuals. This is obviously a formidable task, especially considering the variety of environmental and person factors that can moderate intervention effectiveness. Nevertheless, it seems to us that this task must be initiated in order to: (i) realize progress in the development of more effective intervention 
programs for those individuals most at risk, and (ii) disseminate behavior change principles and innovative technologies across injury control domains.

Figure 2 offers a framework for conceptualizing the social validity and large-scale significance of behavior change tactics and comprehensive intervention programs.

The multiple intervention level (MIL) hierarchy depicted in Figure 2 is characterized by dividing intervention strategies into multiple tiers or levels, each defined by certain dimensions of intervention effectiveness. At the first (i.e. bottom) level of the MIL hierarchy, the interventions are least intrusive and target the maximum number of people for the least cost per person. Therefore, an intervention at 'Level 1 ' is designed to have maximum large-scale appeal, while allowing only minimal contact between the individual and the intervention agent. Examples include reminder signs, policy statements, media communications, public lectures and demonstrations. Those showing the desired target behavior change

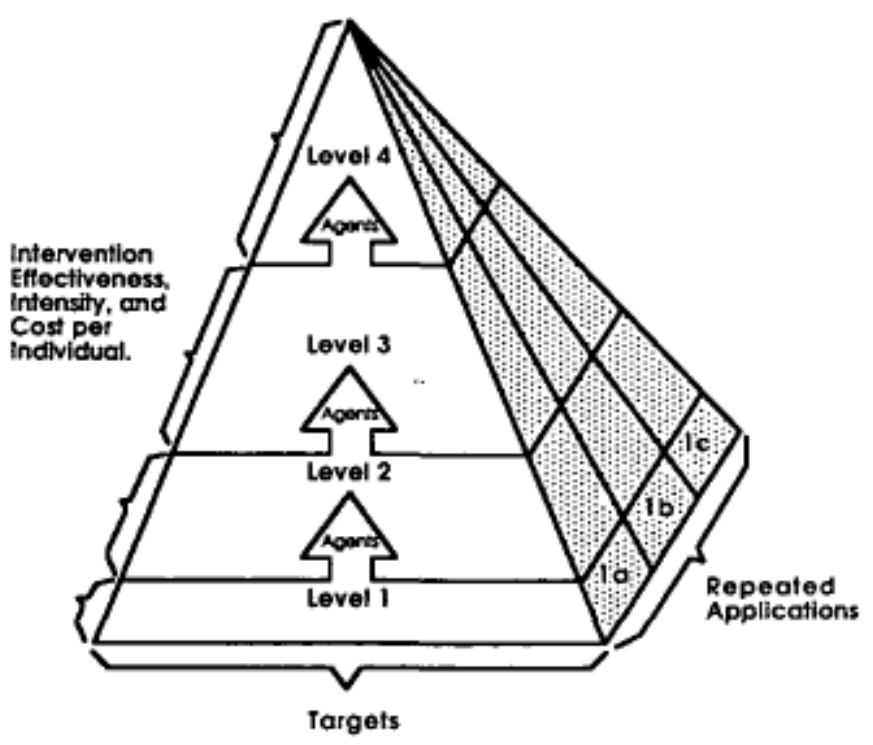

Fig. 2. A multiple intervention level hierarchy differentiating repeated interventions at the same effectiveness level from interventions that are progressively more influential at changing behavior. The height of each intervention level increases progressively from levels 1 to 4 in order to denote successively increasing amounts of intervention effectiveness, intensity, and cost per program 
participant.

at a particular intervention level may continue to benefit from repeated exposure to similar interventions (see 'Repeated Applications' in Figure 2); but we assume that those individuals uninfluenced by the first exposure to a particular intervention level will generally be uninfluenced by repeated exposure to interventions at the same level of effectiveness. These individuals require a higher level (more influential) intervention (i.e. 'level 2' or higher).

Compared with signs, lectures and policy statements, for example, an incentive/reward or disincentive/ penalty program will change the behaviors of more individuals, but it is much more costly to implement these more intensive and effective intervention programs, in terms of personnel, materials and effort. Such programs are actually wasted on individuals who already emit the target behavior (perhaps as the result of a lower-level intervention), but are necessary for the 'hard-core' problem individuals who are not influenced by less intensive (and less costly) behavior change tactics.

Given the propositions and empirical support from problem behavior theory (Jessor, 1987; Melton, 1988; Wilson and Jonah, 1988), those persons most resistant to lower-level interventions are the persons most likely to emit the most damaging (or risky) behaviors. Thus, it seems necessary to find and apply even higher-order interventions (e.g. 'level 3' or 'level 4') for the more risky individuals. One justification for the expense of higher-order interventions is that individuals who continue to pursue risky behaviors can jeopardize individuals engaged in safe behaviors (i.e. those influenced by lower-level interventions). As indicated earlier, for example, the injury control potential of large-scale safety belt use will not be realized until those unresponsive to BULs (generally the riskiest drivers) use their safety belts. Accordingly, it may be more cost-effective in the long run to repeat fewer lower-level interventions (e.g. public service announcements of a BUL) that influence minimal new behavior change, and use the saved resources to implement more effective (i.e. higher-level) intervention programs. Given the proposition that intervention effectiveness varies directly with the number of intervention agents (i.e. behavior change personnel), one challenge for the higher-order 
intervention is to find ways of increasing the intervention agent-to-target ratio.

The MIL model in Figure 2 indicates that individuals who are influenced by a particular level of the intervention hierarchy may become intervention agents for the next higher level of intervention effectiveness (cf. Katz and Lazarfeld, 1955). Thus, after individuals have adopted a particular injury control behavior (e.g. safety belt use), it is not costeffective to include these persons among the targets of a higher-level program to motivate the occurrence of that behavior. Instead, these persons need to be enrolled as agents for higher-level intervention programs. In other words, 'preaching to the choir' is not as beneficial as enlisting the 'choir' to preach to others.

Research is needed to explore ways to involve indigenous personnel in the implementation of successful intervention strategies. At the same time, it is necessary to identify ways of maximizing the effectiveness of the behavior change interventions that these individuals could complement. Actually, strategies that successfully increase the occurrence of injury control behaviors might also be applicable for motivating additional individuals to assist in intervention implementation. We turn now to a description of various behavior change techniques that can be used in an intervention program, and to the consideration of measurable factors that determine the relative behavior-change impact of an intervention program.

\section{Model development to evaluate intervention effectiveness}

\section{Behavior change strategies}

Table I gives brief definitions of 24 different approaches to change behavior, distilled from a comprehensive review of the behavioral science literature that researched techniques for changing behaviors at individual and group levels [representative sources include Cone and Hayes (1980); Glenwick and Jason (1980); Geller, Winett and Everett (1982), and most research articles published in the Journal of Applied 
Passive

\section{Communication/education}

1. Lecture: unidirectional oral communication by an agent concerning the rationale and purpose for behavior change and subsequent intervention. Target subjects are told what behaviors are in their best interest.

2. Demonstration: modeling or acting out appropriate performance or behavior for target subject(s).

3. Policy: a written document communicating the standards, norms, or rules for appropriate performance or behavior within a given context.

\section{Active}

4. Commitment: a written or oral pledge or promise by a subject to perform or behave in a specific way or to attain a certain goal.

5. Discussion/Consensus: bidirectional oral communication between agents or facilitators of an intervention program and the subjects targeted by the intervention. Communication focuses on generating consensus regarding the particular behavior change technique(s) or program.

6. Intervention agent: when a person promotes the desired behavior among other individuals.

Individual

\section{Activators}

7. Written activator: a written communication that attempts to prompt or activate desired performance or behavior.

8. Oral activator: an oral communication that artempts to prompt desired performance.

9. Assigned individual goal: an intervention agent decides for an individual the level of desired behavior he or she should accomplish by a certain time.

10. Personal goal: an intervention agent encourages an individual to decide for him or herself the level of desired behavior (i.e. the goal) he or she should accomplish by a specific time.

11. Competition: an intervention which promotes competition between individuals to see which person will accomplish the desired performance level first (or best).

12. Incentive: an announcement to an individual in written or oral form of the availability of a reward that is dependent upon the occurrence of a desired behavior by the individual, according to a contingency defined by the agent(s) of the intervention.

13. Disincentive: an oral or written announcement to an individual specifying the possibility of receiving a penalty contingent upon the occurrence of a particular undesired behavior. The contingency is defined by the agent(s) of the intervention.

Group

14. Assigned group goal: an agent decides for a group the level of desired performance the participants should accomplish by a certain time.

15. Team goal: an agent encourages group members to decide for themselves (i.e. come to a consensus) that level of desired performance (i.e. the goal) which the group should accomplish by a specific time.

16. Competition: an intervention which promotes competition between specific groups to see which group will accomplish the desired performance level first (or best).

17. Incentive: an oral or written announcement to a group specifying the availability of a group reward that is dependent upon the occurrence of desired group performance, according to a contingency defined by the agent(s) of the intervention.

18. Disincentive: an oral or written announcement to a group that specifies the possibility of receiving a penalty contingent upon . the occurrence of undesired group behavior. The contingency is defined by the agent(s) of the invervention.

Individual

\section{Consequences}

19. Feedback: presentation of either oral or written information to an individual concerning his or her level of performance regarding desired or undesired behavior.

20. Reward:- either the presentation of a 'pleasant' item or event to an individual emitting a desired behavior, or the withdrawal of an 'unpleasant' item or event from an individual for emitting a desired behavior.

21. Penalty:* either the presentation of an 'unpleasant' item or event to an individual emitting an undesired behavior, or the withdrawal of a 'pleasant' item or event from an individual for emitting an undesired behavior.

Group

22. Feedback: presentation of either oral or written information to specific group concerning the participants' level of performance regarding desired or undesired behavior.

23. Reward: either the presentation of a 'pleasant' item or event to a group or team emitting collectively a desired level of performance, or the withdrawal of an 'unpleasant' item or event from a group or team for emitting collectively a desired level of performance. 
Table I. (cont.)

24. Penalty: either the presentation of an 'unpleasant' item or event to a group or team emitting collectively an undesired level of performance, or the withdrawal of a 'pleasant' item or event from a group or team for emitting collectively an undesired level of performance.

*Note: The terms 'reward' and 'penalty' are substituted for 'reinforcement' and 'punishment' because reinforcement and punishment require empirical verification of their effects.

Behavior Analysis, from 1968 until the present]. The first 18 behavior change techniques occur before the target behavior(s), and these are considered antecedent procedures or activators [from the antecedent behaviorconsequence model of applied behavior analysis, cf. Geller, Winett and Everett, (1982)]. All of these activators represent attempts to persuade individuals to emit the desired response and are classified as passive versus active communication/ education techniques or as activators which address individuals or groups.

Feedback, reward and penalty consequences can be given to an individual or to a group and therefore Table I defines six different consequence procedures. Rewards include pleasing items or events as well as opportunities to escape or avoid unpleasant items or events; whereas a penalty can be the presentation of an unpleasant item or event (e.g. a jail term or requirement to do community service) or the removal of a pleasant item or privilege (e.g. money or a driver's license). Our definitions for reward and penalty consequences are analogous to positive versus negative reinforcement and positive versus negative punishment (cf. Geller, Winett and Everett, 1982), except that these latter technical terms from applied behavior analysis are linked directly to behavioral outcome. That is, reinforcement occurs only if the target behavior increases in frequency. If the target response decreases following the consequence, then the behavior change procedure was positive or negative punishment.

It is noteworthy that most intervention programs consist of a variety of the behavior change techniques listed in Table I. Educational programs to promote safety and health, for example, often include discussion/ consensus building, demonstrations, lectures and written activators. And, most programs to increase safety belt use have included varieties of written and oral activators (e.g. signs, newsletters, 
memos, verbal reminders) to announce the intervention program to the potential participants; and then a specific incentive/reward, feedback or commitment strategy was implemented to motivate behavior change. Some programs started with facilitated discussions among potential participants (e.g. a work group) that led to a consensus regarding the details of the behavior change program.

\section{Intervention effectiveness}

We hypothesize that five factors determine the effectiveness of an intervention program, as measured by the proportion of a target population showing desired behavior change over the short and long term, or by the degree to which an individual initiates and maintains the behavior that is targeted by an intervention procedure. Based on our literature review and empirical studies of safety belt promotion, we theorize that the immediate impact of an intervention is a direct function of: (i) the amount of participant involvement elicited by the intervention; (ii) the degree of group or social support promoted by the intervention procedures; (iii) the amount of specific response information transmitted by the intervention; (iv) the degree of extrinsic control exerted by the intervention; ( $v$ ) the target individual's perception of autonomy or self control regarding the behavior change procedures.

We further presume that: (i) program involvement is a direct function of the amount of behavioral activity resulting from the intervention, and this is generally a direct function of the agent-to-target ratio (i.e. more intervention agents per target population usually promote greater participant involvement); (ii) social support is influenced by the degree of interactive peer, family or friend advocacy facilitated by the intervention; (iii) response information varies directly with the amount of new behavioral knowledge given by the intervention, and can be facilitated by increasing the salience of the information presentation and the proximity between the behavioral request and the individual's opportunity or ability to emit the desired response (cf. Geller, Winett and Everett, 1982); (iv) extrinsic control is determined by the implementation of certain response contingencies (i.e. positive versus negative reinforcement or punishment); (v) autonomy is increased by individual perceptions of intrinsic control and freedom 
of choice.

Person factors (see Figure 1) are also relevant here, since the effectiveness of a behavior change technique is determined by characteristics of both the administrator and the recipient of the intervention program. Measurable characteristics of the program recipient, for example, that might influence intervention effectiveness include: (i) an individual's causality orientation (Deci and Ryan, 1987) and perceived locus of control (Strickland, 1989); (ii) a person's natural tendency to interact in group settings (e.g. an extrovert); (iii) the amount of natural social support available to the individual, including family and friend networks and degree of acculturation (i.e. the individual's appreciation or respect for cultural sanctions); (iv) the degree of incompatibility between the target behavior (e.g. safe or healthy practices) and the person's normal lifestyle (e.g. risky and sensation seeking behaviors).

Table II depicts our derivation of an initial taxonomy of behavior change techniques for evaluating intervention impact and for guiding the development of more effective intervention programs. Hopefully, this heuristic will also prompt needed behavior change research in the domain of injury control. For example, empirical evidence is needed to verify our classifications of behavior change procedures and to develop a weighting system to account for the relative influence of the five factors presumed to determine intervention effectiveness. To derive the preliminary factor scores for each behavior change technique, we first defined each behavior change procedure according to recent applications of behavior analysis for promoting health and safety (see Table I), and then we judged whether the procedures and operations inherent in a given behavior change technique included aspects of the five evaluation factors as discussed above (see Table II). A simple all-or-none (present $=1$ versus absent $=0$ ) scoring system was applied as described below. Research is needed to provide behavioral evidence for these judgments, and to develop a more sensitive scoring scheme. For example, differential observations of involvement and social support across different intervention programs (e.g. discussion/consensus versus intervention agent) would suggest ratings of 'degree' rather than 'all-or-none'. (A 'degree' could be created by calculating a regression coefficient or factor loading.) The factor scores given in Table II for each of the 
intervention techniques defined in Table I were determined by scoring $a$ ' 1 ' if any of the following questions per factor were answered affirmatively.

\section{Involvement}

Does the behavior change technique set the occasion for overt participant action relevant to the target behavior?

\section{Social support}

Does the behavior change procedure include opportunities for continual program-relevant support from program participants or other individuals or groups (e.g. family, friends, work groups)?

\section{Response information}

Does the behavior change procedure offer new and specific information relevant to the behavior(s) targeted? This was a difficult factor to judge because the amount of response information depends upon the particular message used for the behavior change technique and the program recipient's prior knowledge of the target behavior. For example, written activators (e.g. signs or memos that specify desired behaviors) are often informative for the initial exposure to viewers; however, after individuals become aware of the appropriate response, the same activator essentially becomes a reminder (with less response information upon repeated presentations). Thus, while lectures, discussions and demonstrations usually provide new response information to an individual, verbal activators (e.g. response suggestions in everyday conversations) are often only reminders. Intervention research is needed to develop a plan for scoring the information value of a particular behavior change strategy as it relates to 
Table II. A taxonomy of behavior change strategies to guide intervention development and evaluation

\begin{tabular}{|c|c|c|c|c|c|c|c|}
\hline $\begin{array}{l}\text { Behavior change } \\
\text { techniques }\end{array}$ & Involvement & $\begin{array}{l}\text { Social } \\
\text { support }\end{array}$ & $\begin{array}{l}\text { Response } \\
\text { information }\end{array}$ & $\begin{array}{l}\text { Extrinsic } \\
\text { control }\end{array}$ & $\begin{array}{l}\text { Immediate } \\
\text { effects }\end{array}$ & $\begin{array}{l}\text { Intrinsic } \\
\text { control }\end{array}$ & $\begin{array}{l}\text { Long term } \\
\text { effects }\end{array}$ \\
\hline \multicolumn{8}{|l|}{ Communication } \\
\hline \multicolumn{8}{|l|}{ Passive } \\
\hline 1. Lecture & 0 & 0 & 1 & 0 & 1 & 0 & 1 \\
\hline 2. Demonstration & 0 & 1 & 1 & 0 & 2 & 0 & 2 \\
\hline 3. Policy & 0 & 0 & 1 & 0 & 1 & 0 & 1 \\
\hline \multicolumn{8}{|l|}{ Active } \\
\hline 4. Commitment & 1 & 0 & 1 & 0 & 2 & 0 & 2 \\
\hline 5. Discussion/Consensus & 1 & 1 & 1 & 0 & 3 & 0 & 3 \\
\hline 6. Intervention agent & 1 & 1 & 1 & 0 & 3 & 0 & 3 \\
\hline \multicolumn{8}{|l|}{ Activators } \\
\hline \multicolumn{8}{|l|}{ Individual } \\
\hline 7. Written activator & 0 & 0 & 1 & 0 & 1 & 0 & 1 \\
\hline 8. Oral activator & 0 & 1 & 1 & 0 & 2 & 0 & 2 \\
\hline 9. Assigned individual goal & 0 & 0 & 1 & 1 & 2 & -1 & 1 \\
\hline 10. Personal goal & 1 & 0 & 1 & 1 & 3 & 0 & 3 \\
\hline 11. Competition & 1 & 0 & 1 & 1 & 3 & -1 & 2 \\
\hline 12. Incentive & 1 & 0 & 1 & 1 & 3 & -1 & 2 \\
\hline 13. Disincentive & 1 & 0 & 1 & 1 & 3 & -1 & 2 \\
\hline \multicolumn{8}{|l|}{ Group } \\
\hline 14. Assigned group goal & 0 & 0 & 1 & 1 & 2 & -1 & 1 \\
\hline 15. Team goal & 1 & 1 & 1 & 1 & 4 & 0 & 4 \\
\hline 16. Competition & 1 & 1 & 1 & 1 & 4 & -1 & 3 \\
\hline 17. Incentive & 1 & 1 & 1 & 1 & 4 & -1 & 3 \\
\hline 18. Disincentive & 1 & 1 & 1 & 1 & 4 & -1 & 3 \\
\hline \multicolumn{8}{|l|}{ Consequences } \\
\hline \multicolumn{8}{|l|}{ Individual } \\
\hline 19. Feedback & 0 & 0 & 1 & 0 & 1 & 0 & 1 \\
\hline 20. Reward & 0 & 0 & 1 & 1 & 2 & -1 & 1 \\
\hline 21. Punisher & 0 & 0 & 1 & 1 & 2 & -1 & 1 \\
\hline \multicolumn{8}{|l|}{ Group } \\
\hline 22. Feedback & 0 & 1 & 1 & 0 & 2 & 0 & 2 \\
\hline 23. Reward & 0 & 1 & 1 & 1 & 3 & -1 & 2 \\
\hline 24. Punisher & 0 & 1 & 1 & 1 & 3 & -1 & 2 \\
\hline
\end{tabular}

effectiveness at increasing injury-prevention behaviors.

\section{Extrinsic control}

Does the behavior change procedure manipulate a response consequence (i.e. a reward or penalty) in order to influence a target behavior?

\section{Intrinsic control}

Does the behavior change procedure offer an 
opportunity for personal choice or control? This was the most difficult factor to score reliably, but it may be the most critical when considering long-term response maintenance in the absence of the intervention context. Note that we only used this factor when totalling the points for the 'Long term effects' column. The motivational literature (briefly reviewed earlier) persuaded us to assign a score of ' -1 ' to procedures which offer rewards or threaten penalties. Further research is needed to develop a more valid and sensitive scoring system for this factor, including the weighting of negative scores according to the particular target behavior. For example, certain driving behaviors (e.g. safety belt and turn-signal use) require relatively little inconvenience and can readily become habitual; and therefore when a successful extrinsic control contingency is removed, behaviors such as these may not decrease as substantially as other behaviors (e.g. compliance with vehicle speed limits), which are less automatic and are influenced by other interacting environmental and personal factors (e.g. one's motives for making a particular vehicle trip in impending traffic).

As mentioned earlier, a particular intervention program usually consists of a number of behavior change components, and would therefore receive a composite score by adding the relevant numbers from Table II. For example, the incentive/reward safety belt program evaluated by Geller (1983) included flyers (a written activator) to encourage safety belt use and announce the availability of contest symbols to drivers using safety belts (an individual incentive), and the delivery of immediate reward coupons to drivers using safety belts when entering an industry parking lot (an individual reward). Thus, this program would receive a composite, relative effectiveness score of ' 6 ' for immediate effects (i.e. 1 point for the flyer or written activator that urged safety belt use, 3 points for the individual incentive announced on the flyer, and 2 points for the individual rewards) and a score of ' 4 ' for long term impact (2 points were subtracted for the extrinsic control of the individual incentive and reward components, see Table II).

In contrast, a more recent safety belt program developed for pizza deliverers (Ludwig and Geller, 1990) included a discussion/consensus meeting among the store employees to enlist support and ideas for the program (3 points for immediate effects and 
3 points for long term effects), pledge cards to obtain individual commitment to buckle-up (2 points for both immediate and long term effects), 'buckle-up' signs in the store as written activators for employees to use their safety belts ( 1 point for both immediate and long term effects), and verbal 'buckle-up' reminders between employees as oral activators (2 points for both immediate and long term effects). The immediate impact of this program gets a composite score of ' 8 '. In this program, however, no points were subtracted for extrinsic control, and therefore the long term effect also receives a composite score of ' 8 '.

The composite scores for the two programs defined above (i.e. 6 versus 8 for immediate effects and 4 versus 8 for long term impact, respectively) may not be robust predictors of relative program impact with this initial scoring system, especially given the marked differences in the program participants (i.e. differential person factors) and the environmental settings (i.e. different environmental variables). Actually, the relative influence of a particular behavior change technique could only be studied systematically by comparing the impact of two programs implemented among similar participants in similar settings with similar components, except that one program included an additional behavior change technique (i.e. the one to be evaluated). Thus, the examples above were not given to validate our taxonomy, but only to illustrate an application of the scoring system. It is noteworthy, however, that the immediate behavior change effects of the Geller (1983) and Ludwig and Geller (1990) programs were similar (as suggested by similar taxonomy scores of 6 and 8, respectively); but during program withdrawal, employee safety belt use decreased more substantially after the Geller intervention than after the Ludwig and Geller program (and this is as predicted by the long term impact scores of 4 versus 8 , respectively).

Obviously, the domain of injury control is a long way from having a taxonomy of behavior change procedures from which to choose for certain persons and environments. The 24 behavior change strategies listed in Tables I and $\mathrm{n}$ have been used successfully to change various community-based behaviors (e.g. Cone and Hayes, 1980; Glenwick and Jason, 1980; Geller, Winett and Everett, 1982), but studies comparing intervention effectiveness across two or 
more techniques are practically nonexistent. Our attempts to compare intervention impact across studies in the behavior change literature have revealed several compromising problems, including the fact that it is extremely difficult to make comparisons across different target behaviors and environmental contexts. Even with the same target behavior (e.g. safety belt use) and environment (e.g. the workplace), procedural details across studies are often difficult to match up, and differential baseline levels of belt use (partially due to varying person factors across population samples) markedly influence the impact of any intervention program (cf. Geller et al., 1987). We believe that research is needed to address specifically the relative impact of various techniques for increasing injury-prevention responses. By offering a list of behavior change techniques and suggesting an initial scoring system for evaluating intervention efficacy, we have suggested directions for field research that is critically needed in the areas of health, safety and injury control.

\section{Conclusions}

While identifying needs for intervention research, this paper also shows the difficulty in motivating people to emit behaviors to prevent personal injury, even when the behavior is as convenient and protective as buckling a vehicle safety belt. Indeed, the difficulty in increasing the large-scale occurrence of safety belt use in the United States beyond the 50\% levels attained following belt use laws has prompted the development of automatic protection devices (e.g. passive shoulder belts and air bags). The development and implementation of devices that protect individuals from injury without requiring any response cost represents primarily the 'environment' side of the triad depicted in Figure 1, and such automation is certainly desirable. However, it is usually impossible to eliminate the human element (i.e. the person and behavior factors of the triad). To be optimally protective, for example, air bags require safety belt use, and many automatic shoulder belts (e.g. on Chrysler, Ford, Nissan and Toyota vehicles) require manual hook-up of front-seat lap belts. Actually a current challenge facing safety professionals is to convince the public that these automatic safety devices, which increased the purchase price of their vehicles, are not substitutes for their manual safety belts. 
Consider also that automatic safety systems cannot substitute completely for manual safety behaviors because the voluntary occurrence of an injuryprotection behavior may have critical response generalization advantages. Specifically, if an automatic safety system (e.g. the passive shoulder and lap belts in several GM vehicles) eliminates the need or opportunity for a convenient voluntary safety behavior (e.g. buckling a manual lap and shoulder belt), an opportunity for response generalization is lost. In other words, when an individual voluntarily emits a particular response for personal safety or health, there may be an increased probability that this person will emit other similar behaviors. For example, Streff and Geller (1987) found that following a successful awareness and commitment program

that targeted only the use of protective devices (i.e. gloves, safety glasses and ear plugs) on the job, employees increased their use of vehicle safety belts by $174 \%$ (from $12.8 \%$ during baseline to $35.1 \%$ after the occupational safety intervention). Also, the safety belt program examined earlier that increased the use of shoulder belts among pizza deliverers by $143 \%$ over baseline, also increased these individuals' use of turn signals by $25 \%$ when they left the store's parking lot (Ludwig and Geller, 1990). Similarly, high-speed drivers were less likely to be buckled up than medium- and low-speed drivers (Preusser et al., 1988); and drivers using vehicle safety belts while traveling on a busy highway were observed to keep significantly greater headway distances between their vehicle and the vehicle in front of them than drivers who had not buckled up (Evans et al., 1982).

The internal process mediating demonstrations of response generalization might be personal commitment, internal justification, attitude formation or attitude change; and further research and theory development is certainly needed in this area. Nevertheless, the potential occurrence of generalization among injury-protective behaviors offers additional justification for continuing the challenge of motivating behavior change with procedures that allow for individual perceptions of voluntary control. The present paper addressed issues and suggested research directions and opportunities in this critical domain of behavior modification for health and safety. The development of a cogent and comprehensive 
database and theoretical framework will certainly

be challenging, but the potential payoffs are

immeasurable. In other words, there will be a direct

relationship between response cost (or effort) and the

consequential intrinsic and extrinsic rewards.

\section{Acknowledgments}

The development of the theory and conceptualizations presented in this paper was supported by Grant

Number R49CCR302635 from the Centers for

Disease Control, Atlanta, GA, USA.

\section{References}

Bandura.A. (1989) Human agency in social cognitive theory. American Psychologist, 44, 1175 - 1184.

Campbell.R.J., Hunter.W.W., Stewart.J.R. and Stutts,J.C. (1982) Increasing Safety Belt Use Through an Incentive Program (Final report for Innovative Grant Project 4-A22 from the U.S. Department of Transportation). UNC Highway Safety Research Center, Chapel Hill, NC.

Campbell,R.J., Hunter.W.W. and Stutts.J.C. (1984) The use of economic incentives and education to modify safety belt use behavior of high school students. Health Education, 15, 30-33.

Campbell,R.J., Stewart.J.R. and Campbell,F.A. (1987) 1985-1986 Experiences with Belt Laws in the United Stales. UNC Highway Safety Research Center, Chapel Hill, NC.

Campbell.R.J., Stewart.J.R. and Campbell.F.A. (1988) Changes in Death and Injury Associated with Safety Belt Laws: 1985-1987. UNC Highway Safety Research Center, Chapel Hill, NC.

Cone,J.D. and Hayes.S.C. (1980) Environmental Problems: Behavioral Solutions. Brooks/Cole, Monterey, CA.

Deci,E.L. (1975) Intrinsic Motivation. Plenum, New York.

Deci.E.L. and Ryan,R.M. (11987) The support of autonomy and the control of behavior. Journal of Personality and Social Psychology, 53, 1024-1037.

Donovan.D.M., Marlatt.G.A. and Salzberg,P.M. (1983) Drinking behavior, personality factors and high risk driving: A review and theoretical formulation. Journal of Studies on Alcohol, 44, 
395-428.

Elman.D. and Killebrew.T.J. (1978) Incentives and seat belts: Changing a resistant behavior through extrinsic motivation. Journal of Applied Social Psychology, 8, 72-83.

Evans.L., Wasielewski,P. and von Buseck.C.R. (1982) Compulsory seat belt usage and driver risk-taking behavior. Human Factors, 24, 41-48.

Geller,E.S., (1983) Rewarding safety belt usage at an industrial setting: Tests of treatment generality and response maintenance. Journal of Applied Behavior Analysis, 16, 189-202.

Geller,E.S. (1984) Motivating safety belt use with incentives: A critical review of the past and a look to the future. SAE Technical Paper Series (No. 840326). Society of Automotive Engineers, Warrendale, PA.

Geller.E.S. (1988) A behavioral science approach to transportation safety. Bulletin of the New York Academy of Medicine, 65, 632-661.

Geller.E.S. (1989a) Behavior Change Strategies for Improving Road Safety. Invited address to the SWOV Institute for Road Safety Research, Leidschendam, The Netherlands, November 30, 1989.

Geller.E.S. (1989b) Intervening to increase children's use of safety belts. Alcohol, Drugs and Driving, 5, 37-59.

Geller,E.S. (1990) Preventing injuries and deaths from vehicle crashes: Encouraging belts and discouraging booze. In Edwards.J., Tindale,R.S., Heath,L. and Posavac.E. (eds). Social Influence Processes and Prevention, pp 249-277. Plenum Press, New York.

Geller.E.S., Bruff.C.D. and Nimmer,J.G. (1958) 'Hash for Life': Community-based prompting for safety belt promotion. Journal of Applied Behavior Analysis, 18, 145-159.

Geller.E.S., Johnson,R.P. and Pelton,S.L. (1982) Communitybased interventions for encouraging safety belt use. American Journal of Community Psychology, 10, 183 - 195.

Geller.E.S., Lehman.G.R. and Kalsher.M.J. (1989). Behavior Analysis Training for Occupational Safety. Make-A-Difference Inc., Newport, VA.

Geller.E.S., Paterson,L. and Talbott.E. (1982) A behavioral analysis of incentive prompts for motivating seat belt usage. 
Journal of Applied Behavior Analysis, 15, 403-415.

Geller,E.S., Winett,R.A. and Everett.P.B. (1982) Preserving the Environment: New Strategies for Behavior Change. Pergamon Press, New York.

Geller.E.S., Rudd,J.R., Kalsher.M.J., Streff.F.M. and Lehman.G.R. (1987) Employer-based programs to motivate safety belt use: A review of short and long-term effects. Journal of Safety Research, 18, 1-17.

Glenwick.D. and Jason,L. (eds) (1980) Behavioral Community Psychology: Progress and Prospects. Praeger, New York. Injury in America: A Continuing Public Health Problem (1985) National Academy Press, Washington DC.

Jessor.R. (1987) Risky driving and adolescent problem behavior: An extension of problem behavior theory. Alcohol, Drugs and Driving, 3, 1-11.

Jonah,B.A. (1989) Occupant Restraint Use in Canada: Past, Present and Future. Invited address to the SWOV Institute for Road Safety Research, Leidschendam, The Netherlands,

November 30, 1989.

Katz,E. and Lazarfeld.P.E. (1955) Personal Influence: The Part Played by People in the Flow of Mass Communication. Free Press, Glencoe, IL.

Lehman.G.R. and Geller.E.S. (1989). Participative education for children: an effective approach to increase safety belt use. Journal of Applied Behaviour Analysis, 23.

Lepper.M. (1981) Intrinsic and extrinsic motivation in children: Detrimental effects of superfluous social controls. In Collins,W. (ed.), Aspects of the Development of Competence: The Minnesota Symposium on Child Psychology, 14, 155-160.

Lepper,M., Green.D. and Nisbett,R. (1973) Undermining children's intrinsic interest with extrinsic rewards: A test of the overjustification hypothesis. Journal of Personality and Social Psychology, 28, 129-137.

Ludwig.T.D. and Geller,E.S. (1990) Intervening to Increase the Safety Belt Use of Pizza Deliverers: Individual Differences and Response Generalization. Under editorial review.

Melton.G.B. (1988) Adolescents and prevention of AIDS. Professional Psychology: Research and Application, 19, 403-408. 
Preusser,D.F., Lund.A.K., Williams,A.F. and Blomberg.R.D. (1988) Belt use by high-risk drivers before and after New York's seat belt use law. Accident Analysis and Prevention, 20, 245-250.

Preusser.D.F., Williams,A.F. and Lund.A.K. (1985) The Effect of New York's Seat Belt Use Law on Teenage Drivers. Insurance Institute for Highway Safety, Washington, DC.

Roberts.M.C. and Fanurik,D. (1986) Rewarding elementary school children for their use of safety belts. Health Psychology, 5, 185-196.

Roberts.M.C. and Layfield.D.A. (1987) Promoting child passenger safety: A comparison of two positive methods. Journal of Pediatric Psychology, 12, 257-271.

Roberts.M.C. and Turner.D.S. (1986) Rewarding parents for their children's use of safety seats. Journal of Pediatric Psychology, 11, 25-36.

Robertson,L.S. (1983) Injuries: Causes, Control Strategies, and Public Policy. D.C.Heath and Company, Lexington, MA.

Sleet.D.A. (1987) Motor vehicle trauma and safety belt use in the context of public health priorities. The Journal of Trauma, $27,695-702$.

Streff.F.M. and Geller.E.S. (1986) Strategies for motivating safety belt use: The application of applied behavior analysis. Health Education Research: Theory and Practice, 1, 47-59.

Streff.F.M. and Geller.E.S. (1987) An Effective Awareness and Commitment Program for Occupational Safety: Evidence of Response Generalization. Unpublished manuscript. Blacksburg, VA: Virginia Polytechnic Institute and State University.

Strickland.B.R. (1989) Internal-external control of expectancies: From contingency to creativity. American Psychologist, 44, 1-12.

Thyer.B.A. and Geller.E.S. (in press) Behavior analysis in the promotion of safety belt use: A review. In Hersen.M., Miller.P. and Eisler,R. (eds), Progress in Behavior Modification. Sage, Newbury Park, CA.

Thyer.B.A., Geller.E.S., Williams.M. and Purcell.S. (1987) Community-based 'flashing' to increase safety belt use. The Journal of Experimental Education, 53, 155 - 159. 
van Houten,R. and Nau.P.A. (1983) Feedback interventions and driving speed: A parametric and comparative analysis. Journal of Applied Behavior Analysis, 16, 253-281.

van Houten.R., Nau,P.A. and Marini,Z. (1980) An analysis of public posting in reducing speeding behavior on an urban highway. Journal of Applied Behavior Analysis, 13, 383-396.

Wagenaar.A.C. (1984) Restraint Usage Among Crash-Involved Motor Vehicle Occupants. Report UMTRI-84-2. University of Michigan Transportation Research Institute, Ann Arbor, MI.

Waller.J.A. (1987) Injury: Conceptual shifts and prevention implications. Annual Review of Public Health, 8, 21 - 49.

Wilson,R.J. and Jonah,B.A. (1988) The application of problem behavior theory to the understanding of risky driving. Alcohol, Drugs and Driving, 4, 193-204.

Zeigler,P. (1986) Observed safety belt and child safety seat usage at road intersections: 19-city survey results. Research Notes. Office of Driver and Pedestrian Research, National Highway Traffic Safety Administration, US Department of Transportation, Washington, DC. 